\title{
Potential role of odanacatib in the treatment of osteoporosis
}

This article was published in the following Dove Press journal:

Clinical Interventions in Aging

II July 2012

Number of times this article has been viewed

\section{Kong Wah Ng}

Department of Endocrinology and Diabetes and St Vincent's Institute, St Vincent's Hospital, Fitzroy, Victoria, Australia
Correspondence: Kong Wah $\mathrm{Ng}$

Department of Endocrinology and

Diabetes and St Vincent's Institute, St Vincent's Hospital, Level 4, Daly Wing, 35 Victoria Parade, Fitzroy, Victoria 3065, Australia

Tel +6I 392883569

Fax +6I 392883590

Email kongwn@unimelb.edu.au
Abstract: Cathepsin $\mathrm{K}$ is a key enzyme involved in the degradation of organic bone matrix by osteoclasts. Inhibition of bone resorption observed in human and animal models deficient for cathepsin $\mathrm{K}$ has identified this enzyme as a suitable target for intervention by small molecules with the potential to be used as therapeutic agents in the treatment of osteoporosis. Odanacatib (ODN) is a nonbasic selective cathepsin $\mathrm{K}$ inhibitor with good pharmacokinetic parameters such as minimal in vitro metabolism, long half-life, and oral bioavailability. In preclinical studies, ovariectomized monkeys and rabbits treated with ODN showed substantial inhibition of bone resorption markers along with increases in bone mineral density (BMD). Significant differences were observed in the effects of ODN treatment compared with those of other antiresorptive agents such as bisphosphonates and denosumab. ODN displayed compartment-specific effects on trabecular versus cortical bone formation, with treatment resulting in marked increases in periosteal bone formation and cortical thickness in ovariectomized monkeys whereas trabecular bone formation was reduced. Furthermore, osteoclasts remained viable. Phase I and II studies conducted in postmenopausal women showed ODN to be safe and well tolerated. After 5 years, women who received ODN $50 \mathrm{mg}$ weekly continuously from year $1(\mathrm{n}=13)$, showed BMD increases from baseline of $11.9 \%$ at the lumbar spine, $9.8 \%$ at the femoral neck, $10.9 \%$ at the hip trochanter, and $8.5 \%$ at the total hip. Additionally, these subjects maintained a low level of the urine bone resorption marker N-terminal telopeptide/creatinine ( $-67.4 \%$ from baseline) through 5 years of treatment, while levels of serum bone-specific alkaline phosphatase remained only slightly reduced relative to baseline $(-15.3 \%)$. In women who were switched from ODN to placebo after 2 years, bone turnover markers were transiently increased and BMD gains reversed after 12 months off medication. Adverse experiences in the ODN-treated group were not significantly different from the placebo group. In conclusion, available data suggests that cathepsin $\mathrm{K}$ inhibition could be a promising intervention with which to treat osteoporosis. Ongoing studies are expected to provide information on the long-term efficacy in fracture reduction and safety of prolonged treatment with ODN.

Keywords: cathepsin K, selective cathepsin K inhibitors, bone remodeling, osteoclast, bone turnover markers

\section{Introduction}

Major advances in the treatment of osteoporosis have occurred with the introduction of antiresorptive agents represented by bisphosphonates, estrogen receptor modulators, strontium ranelate, and the anabolic agents parathyroid hormone (PTH) 1-34 (teriparatide) and PTH 1-84. More recently, denosumab, a monoclonal antibody against receptor activator of nuclear factor kappa-B ligand (RANKL) was introduced. Nonetheless, the search for affordable, safer, and more effective forms of therapy 
continues because all the therapies currently available to modify bone remodeling have limitations. There is concern that prolonged use of bisphosphonates could lead to a low bone turnover state that would be less able to repair microdamage and allow the accumulation and coalescence of micro-cracks, which are associated with reduced mechanical properties. ${ }^{1}$ In addition, in recent years, attention has been drawn to extremely rare complications associated with bisphosphonate use, such as osteonecrosis of the jaw and atypical subtrochanteric fractures. ${ }^{2,3}$ The use of teriparatide is limited to 24 months in the USA and 18 months in Europe and Australia because an animal toxicology study showed an increased incidence of osteosarcoma. ${ }^{4}$ Clearly, there is scope for the development of novel therapeutic agents with improved safety profiles and efficacy in fracture prevention. Osteoporosis is a common health problem and its incidence is expected to increase in the coming decades as the aged make up a greater proportion of the population.

Advances in our understanding of how osteoclasts resorb bone and communicate with osteoblasts have enabled investigators to identify potential targets in these signaling pathways where appropriate intervention can be expected to achieve substantial inhibition of bone resorption. Cathepsin K is a key enzyme involved in the degradation of organic bone matrix. The inhibition of bone resorption observed in human and animal models deficient for cathepsin $\mathrm{K}$ has identified this enzyme as a suitable target for intervention by small molecules with the potential to be used as therapeutic agents in the treatment of osteoporosis.

\section{Bone remodeling, bone modeling, and coupling}

Bone is a dynamic tissue that is constantly remodeled throughout life. Increased bone remodeling is a feature of postmenopausal osteoporosis and net bone loss in this condition is the result of excess bone resorption over formation. Bone remodeling is the normal physiological mechanism that ensures tissue turnover while maintaining bone mass in the adult. ${ }^{5}$ It provides the mechanism for adaptation to mechanical stress by resorptive removal of micro-damage and repair by bone formation. This remodeling process, which is also an integral part of the calcium homeostatic system, continues throughout adult life. Bone remodeling occurs within discrete units - known as bone remodeling units (BMUs) - throughout the skeleton. Osteoclasts and osteoblasts are active at specific times during the remodeling cycle within each BMU. There is a well-defined sequence of events that is initiated when mechanical deformation or micro-cracks and osteocyte death in old bone generate signals that lead to osteoclasts resorbing bone over a period of about 3 weeks to create resorption cavities. Resorption by osteoclasts is followed by osteoblast activation and formation of osteoid, which fills the resorption cavities over a period of about 3 months. When this active matrix synthesis is completed, osteoblasts become embedded in the matrix to function as osteocytes. Osteocytes continue to play a principal role in initiating bone remodeling by conveying local signals to osteoblasts and osteoclasts on the bone surface via a canalicular system.

Bone modeling, as distinguished from bone remodeling, is the process associated with growth and reshaping of bones in childhood and adolescence. After the epiphyses have fused, growth in width and thickness is accomplished by formation of bone at the periosteal surface with resorption at the endosteal surface.

To preserve the shape and structural integrity of bone, the processes of bone modeling and remodeling must be tightly coordinated through the actions of systemic hormones, locally generated cytokines, and direct cell-cell communication between osteoclasts and osteoblasts. In the physiological state, signaling between osteoclasts and osteoblasts serves to "couple" the rate of bone resorption and formation, so that when resorption increases, formation does also, and when resorption decreases, formation does as well. ${ }^{6}$ There is intense interest in what those coupling mechanisms might be and there is evidence to implicate secreted products of osteoclasts, growth factors released from bone matrix and direct cell-cell contact between osteoclasts and osteoblasts. Mature osteoclasts secrete factors such as cardiotrophin-1, Wnt 10b, BMP-6, sphingosine-1-phosphate, and semaphorin D. ${ }^{7-9}$ When osteoclasts resorb bone, factors such as transforming growth factor beta, insulin-like growth factors 1 and 2, and bone morphogenetic proteins are released from bone matrix to stimulate osteoblast proliferation, differentiation and/or activity. ${ }^{10,11}$ Osteoclasts also regulate osteoblasts by direct cell-cell contact. Ephrin B2, expressed on osteoclast cell membranes, binds to its receptor, Eph B4, expressed on osteoblast cell surfaces to mediate cross talk between these cells through bidirectional signaling. Binding of ephrin B2 and Eph B4 between osteoclast and osteoblast and between osteoblast and osteoblast leads to enhanced osteoblastic differentiation and suppression of osteoclastic activity. ${ }^{12-14}$

For bone structure to be maintained, bone formation and resorption need to be equal, except during growth and throughout aging. During growth there may be a positive BMU balance, with bone formation exceeding bone resorption. After completion of longitudinal growth and with 
the attainment of peak bone strength, the need for a positive BMU balance declines. A negative BMU balance marks the onset of age-related bone loss, with osteoporosis resulting from a persistent excess of resorption over formation.

The fact that bone remodeling is an active and dynamic process enables the use of interventions in the treatment of osteoporosis that limit resorption or augment formation. ${ }^{15}$ Current antiresorptive agents significantly reduce the incidence of fractures, including both vertebral and nonvertebral fractures, particularly hip fractures. ${ }^{16-19}$ However, inhibition of bone resorption by the widely used antiresorptive agents does not restore bone structure or replace bone that has already been lost and is coupled with inhibition of bone formation instead of increased bone formation, which would have been more advantageous for the patient. ${ }^{20,21}$ In contrast, an anabolic drug such as teriparatide increases the rate of bone formation to reduce fracture risk. ${ }^{22,23}$

\section{Osteoclasts}

Osteoblasts express a membrane protein, RANKL, which is regulated by osteotropic hormones such as PTH and calcitriol, as well as cytokines such as interleukin-6. RANKL plays a critical role in osteoclast differentiation, activation, and survival. The binding of RANKL to its receptor, receptor activator of nuclear factor kappa-B, expressed in mononuclear hematopoietic precursors, initiates the processes that ultimately lead to the formation of multinucleate osteoclasts. Osteoprotegerin acts as a decoy receptor for RANKL to suppress osteoclast formation.

To resorb bone, osteoclasts first attach themselves to the bone surface to seal off an extracellular compartment, termed a "resorption lacuna," in which mineralized bone matrix can be resorbed. The attachment of the osteoclast to bone is facilitated by podosomes containing filamentous actin and the alpha-v beta- 3 integrin. The osteoclast becomes morphologically and functionally polarized to form a ruffled border at the apical membrane of the osteoclast facing the resorption lacuna. To achieve acidification of the resorption lacuna and begin the process of bone demineralization, carbonic anhydrase II within the osteoclast generates a proton and bicarbonate from carbon dioxide and water. The proton is actively transported across the membrane of the ruffled border through the action of the osteoclast-specific vacuolar-type $\mathrm{H}^{+}$ ATPase "proton pump" to reduce the $\mathrm{pH}$ to about 4. Passive transport of chloride through a chloride channel coupled to the proton pump facilitates balancing the charge of ions across the membrane. The acid $\mathrm{pH}$ removes the bone mineral, exposing matrix proteins like type I collagen to be degraded by enzymes such as cathepsins, a family of cysteine proteinases that operate under acidic conditions ${ }^{24,25}$ (Figure 1).

\section{New therapeutic agents to treat osteoporosis}

The aims of drug discovery are to develop:

- drugs that reduce fracture risk without long-term deleterious effects on the skeleton or other side effects;

- drugs whose effects cease with cessation of therapy;

- bone resorption inhibitors that do not inhibit bone formation;

- anabolic agents; and

- drugs that are safe, cost-effective, and that act specifically on osteoclasts and/or osteoblasts.

A single drug or combination of drugs that dissociates bone resorption from bone formation could decrease the rate of bone resorption while increasing the rate of bone formation, with the potential for improved clinical outcomes compared with current drug therapy. ${ }^{21}$ In mice deficient for either $c$-src or the chloride-7 channel, bone resorption is inhibited without any inhibition of the rate or extent of formation. ${ }^{26,27}$ In each of these mouse mutations, osteoclast numbers are maintained, but the osteoclasts are unable to resorb bone. This is also the case in human subjects with inactivating mutations either of chloride-7 channel or the vacuolar $\mathrm{H}^{+}$ATPase. ${ }^{28,29}$ These findings suggest that the development of an agent that inhibits bone resorption but permits bone formation could be possible.

This article focuses on the development of specific cathepsin $\mathrm{K}$ inhibitors as potential therapeutic agents in the treatment of osteoporosis, with in vivo evidence suggesting that cathepsin $\mathrm{K}$ inhibitors not only reduce bone resorption but are also capable of dissociating bone resorption from bone formation.

\section{Cathepsin K}

Cathepsins are homeostatic enzymes critically involved in the proteolytic processing of specific substrates. Thus, cathepsins contribute to distinct physiological processes such as antigen presentation in the immune system, collagen turnover in bone and cartilage, and neuropeptide and hormone processing. ${ }^{30}$ Cathepsins are lysosomal proteases that belong to the papainlike cysteine protease family. Eleven different types have been described (B, C, F, H, K, L, O, S, V, X, and W), with cathepsin $\mathrm{K}$ being the most important with respect to bone remodeling, since it is a protease with intense collagenase activity. It is a protein of 329 amino acids that consists of an amino-terminal region of 15 amino acids, a pro-peptide of 99 amino acids, and a catalytic unit of 215 amino acids. ${ }^{31-33}$ 


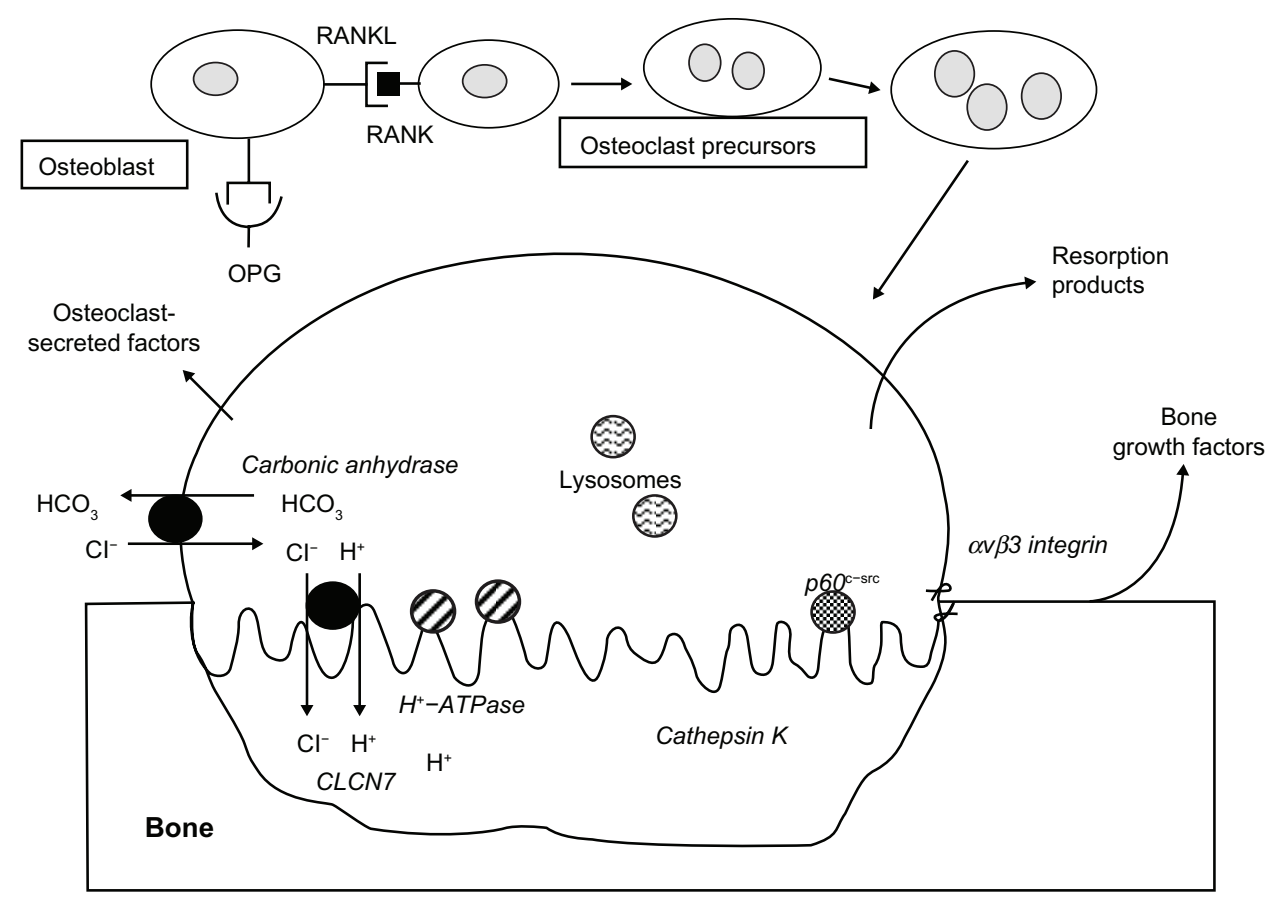

Figure I Osteoblasts express a membrane protein, receptor activator of nuclear factor kappa-B ligand (RANKL), which plays a critical role in osteoclast differentiation, activation, and survival.

Notes: The binding of RANKL to its receptor, receptor activator of nuclear factor kappa-B, expressed in mononuclear hematopoietic precursors, initiates the processes that ultimately lead to the formation of multinucleate osteoclasts. Mature osteoclasts attach to bone surface to seal off an extracellular compartment, termed a "resorption lacuna," in which mineralized bone matrix can be resorbed. The attachment of the osteoclast to bone is facilitated by podosomes containing filamentous actin and the alpha-v beta-3 integrin. The osteoclast forms a ruffled border at the apical membrane of the osteoclast, facing the resorption lacuna. Carbonic anhydrase II within the osteoclast generates a proton and bicarbonate from carbon dioxide and water. The proton is actively transported across the membrane of the ruffled border through the action of the osteoclast-specific vacuolar-type $\mathrm{H}^{+}$-ATPase "proton pump" to reduce the $\mathrm{pH}$ to about 4. Passive transport of chloride through a chloride channel coupled to the proton pump facilitates balancing the charge of ions across the membrane. The acid pH removes the bone mineral, exposing matrix proteins like type I collagen to be degraded by lysosomal enzymes such as cathepsin $\mathrm{K}$ that are secreted into the resorption lacuna. Osteoclast-secreted factors and growth factors released from bone matrix during resorption stimulate osteoblast proliferation, differentiation, and/or activity (see text). Bone resorption products are released into the systemic circulation.

It is predominantly expressed in osteoclasts and is the most abundant cysteine protease in these cells, accumulating in specific subcellular compartments, possibly lysosomal vesicles. In actively resorbing osteoclasts, cathepsin $\mathrm{K}$ is localized at the ruffled border and discharged into the extracellular space when the lysosomal vesicles fuse with the cell membrane, to degrade the two main types of collagen, I and II within the acidic microenvironment of resorption lacunae. ${ }^{34-36}$ Cathepsin K cleaves the N-telopeptide of collagen to generate $\mathrm{N}$-terminal telopeptide (NTX) and degrades serum C-terminal telopeptide of type I collagen (1CTP), to generate C-terminal telopeptide (CTX) ${ }^{37}$

The expression of cathepsin K is downregulated by estrogen and upregulated by RANKL, tumor necrosis factor, and many other agents capable of increasing osteoclast formation and differentiation, such as vitamin D, PTH, and interleukins..$^{38-40}$

\section{Genetic models of cathepsin K deficiency} Pycnodysostosis, derived from the Greek "pycnos" (dense), "dys" (defective), and "ostosis" (bone), was first described in 1962 by Maroteaux and Lamy. ${ }^{41}$ It is a rare osteochondral dysplasia linked to defects in the gene encoding cathepsin $\mathrm{K}^{42}$ The renowned French impressionist painter Henri de Toulouse-Lautrec (1864-1901), was thought to suffer from pycnodysostosis. The disorder is characterized by osteosclerosis and bone fragility with a high fracture risk, reduced stature, acro-osteolysis of the distal phalanges, clavicular dysplasia, hypoplasia of the mandible and skull deformities with delayed suture closure and open fontanels. The characteristic facial appearance includes calvarial bossing, proptosis, overhanging nasal tip, micrognathia, and dental abnormalities. ${ }^{43}$ NTX and CTX levels are low in patients with pycnodysostosis, consistent with decreased bone turnover but no abnormality is seen in markers of bone formation, osteocalcin, or carboxy-terminal pro-peptide of type I collagen, suggesting normal osteoblast activity. ${ }^{44}$

Similar findings were demonstrated in genetically modified mouse models. Cathepsin K-deficient mice exhibit an osteopetrotic phenotype characterized by increased bone volume and in the number and thickness of bone trabeculae. 
Histomophometric analysis of cancellous bone reveals increased bone formation rates (BFRs). Osteoclast number and bone demineralization are normal but osteoclasts fail to resorb the organic bone matrix. ${ }^{45-48}$ In contrast, transgenic mice that overexpress cathepsin $\mathrm{K}$ have reduced trabecular bone volume as a result of accelerated bone turnover. ${ }^{49}$

\section{Specific cathepsin K inhibitors}

The catalytic unit of cathepsin $\mathrm{K}$ is arranged in two domains separated by a cleft that contains the substrate binding site. Peptide inhibitors are designed to inhibit the action of cathepsin $\mathrm{K}$ by binding at this substrate site, mimicking a natural cathepsin K-substrate complex..$^{50,51}$ Ideally, cathepsin $\mathrm{K}$ inhibitors should be of low molecular weight, exhibiting minimal peptide character, and should bind reversibly and highly selectively without affecting other major cysteine cathepsin family members, particularly the closely related cathepsins L, S, and V. The major challenge of the inhibitor design also requires standard drug-like properties such as oral bioavailability with high pharmacological profiles (high membrane permeability, long plasma half-lives, slow elimination rates, no or low toxicity) for acute and chronic use. Cathepsin $\mathrm{K}$ inhibitors have to be delivered into the lysosomes, but, in contrast to bisphosphonates, they do not need to bind to bone in order to exert their action. ${ }^{52}$ It is the concentration of these drugs in the resorption lacunae that is most relevant to their activity. ${ }^{53}$

Because cathepsin $\mathrm{K}$ and most other cathepsins are lysosomal enzymes, early inhibitors were designed to contain lipophilic and basic moieties to allow cell permeability and localization to lysosomes (lysosomotropism). However, their increased accumulation in acidic lysosomes resulted in the inhibition of other cysteine proteases such as B and L, causing undesired effects. ${ }^{5-56}$ The strategy subsequently shifted to the design of nonbasic inhibitors, which are non-lysosomotropic but still maintain their potency and selectivity against individual cathepsins and in vivo efficacy in animal studies. ${ }^{57,58}$ Rodent and rabbit cathepsin K has $88 \%$ and $94 \%$ homology with human cathepsin $\mathrm{K}$, respectively, while monkey and human cathepsin $\mathrm{K}$ are identical, making the use of nonhuman primate models more appropriate for studying these inhibitors in vivo. ${ }^{59-61}$

\section{L-006235}

L-006235, a selective, basic cathepsin K inhibitor, administered orally to ovariectomized (OVX) rhesus monkeys once daily for 7 days, resulted in a dose-dependent decrease in bone resorption. ${ }^{62}$ When given once daily for 27 weeks to adult newly OVX rabbits, L-006235 blocked bone loss with efficacy similar to alendronate. However, unlike alendronate, L-006235 had no effect on cancellous and endocortical mineralizing surface or on Haversian bone formation.

\section{Relacatib}

Relacatib is an equipotent inhibitor of cathepsins $\mathrm{K}, \mathrm{L}$, and V while exhibiting some selectivity against cathepsins $\mathrm{S}$ and B. ${ }^{63,64}$ It is a nonbasic 5-, 6-, and 7-methyl-substituted azepanone analog (SB-462795; GlaxoSmithKline, London, UK). A decrease in bone resorption is observed when administered to OVX monkeys. Relacatib also reduces bone formation at cancellous sites while increasing femur periosteal bone - possibly due to transiently increased plasma PTH levels. ${ }^{65,66}$ Relacatib was discontinued following a Phase I study that showed possible drug-drug interactions with the commonly prescribed medications paracetamol, ibuprofen, and atorvastatin. ${ }^{60}$

\section{Balicatib}

Balicatib (AAE-581) is a highly selective nitrogen-containing inhibitor of cathepsin K with properties of lysosomotropism. ${ }^{67}$ It prevented OVX-induced loss of vertebral and femoral bone mineral density (BMD), increased bone strength, and suppressed the cancellous BFR, while increasing periosteal bone formation and cortical thickness in monkeys. ${ }^{68}$ In a 1-year doseranging study in postmenopausal women, balicatib at 25 and $50 \mathrm{mg}$ reduced serum CTX by $61 \%$ and urinary NTX by $55 \%$. However, serum bone formation markers (osteocalcin, BSAP, and P1NP) were not reduced by the 10,25 , and $50 \mathrm{mg}$ doses, and were increased in the $5 \mathrm{mg}$ dose group. There were dosedependent BMD increases in lumbar spine and hip of $4.5 \%$ and $2.2 \%$, respectively. ${ }^{69}$ Balicatib trials were discontinued due to dermatologic adverse effects, including a morphea-like syndrome. ${ }^{70}$ It is possible that the skin toxicities were caused by increased accumulation of balicatib in the lysosomes of human skin fibroblasts, in which cathepsins B and L are highly expressed and localized along with cathepsin $\mathrm{K} \cdot{ }^{33,54}$

\section{ONO-5334}

ONO-5334 (Ono Pharmaceutical Company, Ltd, Osaka, Japan) is a low-molecular-weight synthetic inhibitor of cathepsin $\mathrm{K}$ being developed as a therapeutic agent for bone metabolic diseases including osteoporosis. ONO-5334 has shown improvement in both BMD and bone strength in the ovariectomized monkey osteoporosis model..$^{70-72}$

In the Phase II OCEAN study, 295 postmenopausal women with osteoporosis were randomly assigned to one 
of five treatment arms: (1) $50 \mathrm{mg}$ twice daily, (2) $100 \mathrm{mg}$ daily, or (3) $300 \mathrm{mg}$ daily, (4) alendronate, or (5) placebo for 12 months with a 12-month extension. The primary outcome measure was BMD at the lumbar spine. At month 24, $300 \mathrm{mg}$ ONO-5334 suppressed bone resorption markers as potently as alendronate. While alendronate maintained suppression of bone formation markers, ONO-5334 did not show suppression even at the highest dose. The $300 \mathrm{mg}$ dose of ONO-5334 had no effect on TRAP5b, while this was significantly suppressed by alendronate. All doses of ONO5334 resulted in significant and dose-dependent increases in spine and hip BMD versus placebo. At month 24, $300 \mathrm{mg}$ ONO-5334 increased lumbar spine BMD by $6.7 \%$, total hip BMD by $3.4 \%$, and femoral neck BMD by $3.7 \%$. Alendronate $\mathrm{BMD}$ results for lumbar spine, total hip, and femoral hip were $6.3 \%, 4.2 \%$, and $2.9 \%$, respectively. ${ }^{73}$

Studies with L-006235, relacatib, and balicatib have been discontinued, while the results of a Phase II study of ONO-5334 were published last year. Odanacatib (ODN) is the only specific cathepsin K inhibitor currently undergoing Phase III studies.

\section{ODN}

ODN (MK-0822; Merck and Co, Inc, Whitehouse Station, $\mathrm{NJ}$ ) is a nonbasic and non-lysosomotropic nitrile-based molecule displaying high potency for cathepsin $\mathrm{K}\left(\mathrm{IC}_{50}=0.2 \mathrm{nM}\right)$ and increased selectivity versus cathepsins $\mathrm{B}, \mathrm{L}$, and $\mathrm{S}$ when compared with balicatib and relacatib. In preclinical studies, ODN presented good pharmacokinetic parameters such as minimal in vitro metabolism and long half-life, and oral bioavailability. ${ }^{32,60}$ In OVX rabbits, ODN inhibited bone resorption without decreasing bone formation. ${ }^{74}$

Two related studies in OVX monkeys that evaluated the effects of ODN on bone turnover, BMD, and bone strength had findings that were common with conventional antiresorptives and other findings that were different. ${ }^{75,76}$ OVX monkeys were treated for 21 months with either vehicle, ODN $6 \mathrm{mg} / \mathrm{kg}$, or ODN $30 \mathrm{mg} / \mathrm{kg}$ (orally, once daily), and compared with intact animals. ODN treatment persistently suppressed bone resorption markers (urinary NTX by $75 \%$ to $90 \%$ and serum CTX by $40 \%$ to $55 \%$ ) and serum bone formation markers (BSAP by $30 \%$ to $35 \%$ and P1NP by $60 \%$ to $70 \%$ ) versus vehicletreated OVX monkeys. In the lumbar vertebrae and iliac crest, both doses of ODN prevented bone loss and maintained bone mass at a level comparable to intact animals. BFRs in trabecular bone at the iliac crest and lumbar vertebrae decreased by comparable amounts. However, in the femoral neck and proximal femur, there was no effect on endocortical BFR, while trabecular and intracortical BFR were reduced. Furthermore, ODN stimulated long-term femoral neck and proximal femur periosteal BFR by 3.5-fold and 6-fold, respectively, with the $30 \mathrm{mg} / \mathrm{kg}$ dose versus vehicle, resulting in a $21 \%$ and $19 \%$ increase in cortical thickness in the femoral neck and proximal femur, respectively. Thus, unlike conventional antiresorptives, ODN displayed compartment-specific effects on trabecular versus cortical bone formation, with treatment resulting in marked increases in periosteal bone formation and cortical thickness in OVX monkeys, whereas trabecular bone formation was reduced. This compartment-specific effect of ODN in OVX monkeys is similar to that previously reported for balicatib and relacatib. Another point of difference from current antiresorptives is the maintenance of osteoclast numbers in the ODN-treated groups compared with the vehicle controls. If the osteoclasts remain viable, they could still be functional, even though they could no longer resorb bone. Serum level of TRAP5b, an indicator of osteoclast cell number and biomarker of osteoclast viability was maintained, providing support for the distinct mechanism of cathepsin $\mathrm{K}$ inhibition in effectively suppressing bone resorption without reducing osteoclast numbers. ${ }^{77,78}$

These findings, suggesting a compartment-specific effect of bone resorption and bone formation through cathepsin $\mathrm{K}$ inhibition, may represent a novel therapeutic approach for the treatment of osteoporosis.

A preclinical study showed that ODN can be effectively combined with an anabolic agent such as PTH. This study with estrogen-deficient rabbits compared the effect of five different treatment regimens on BMD, bone histology, and bone strength: the combinations of human PTH 1-34 and ODN, PTH and alendronate, and the monotherapies including ODN, alendronate, or PTH. Treatment with $\mathrm{PTH}+\mathrm{ODN}$ resulted in the fastest rate of BMD gain. Bone histology showed that although both the PTH+ODN and PTH+alendronate combinations resulted in increases in $\mathrm{BMD}$, the $\mathrm{PTH}+$ alendronate combination eventually halted bone formation in the trabecular lumbar vertebrae, whereas the $\mathrm{PTH}+\mathrm{ODN}$ combination increased BMD and BFR. ${ }^{79}$

\section{Cathepsin K inhibition by ODN in human studies \\ Phase I trials}

Two Phase I trials were conducted to determine safety, tolerability, pharmacokinetics, and pharmacodynamics of ODN based on biomarkers of bone turnover. ${ }^{33,80-82}$

Three doses of ODN $(0.5,2.5$, and $10 \mathrm{mg})$ were administered once daily to 30 postmenopausal female subjects 
$(\mathrm{n}=10$ per group [eight active, two placebo]) for 21 days in the first Phase I study ${ }^{81}$ In the second Phase I study, 48 postmenopausal female subjects were divided into four groups (nine active, three placebo) and administered 5, 25, 50, and $100 \mathrm{mg}$ ODN or placebo once weekly for 3 weeks. ${ }^{81}$

Dose-dependent decreases in CTX and NTX/creatinine (Cr) were observed, reaching a maximal effect following once-weekly doses of $\geq 50 \mathrm{mg}$ or once-daily doses of $\geq 2.5 \mathrm{mg}$. At these doses, maximal suppression (CTX, $62 \%$; NTX/Cr, $62 \%$ at day 21 with $50 \mathrm{mg}$ ) was evident by day 2 in the first week of weekly dosing with $50 \mathrm{mg}$ ODN, and maintained at steady state over the dosing interval. Similarly, maximal suppression (CTX, 69\%; NTX/Cr, 79\% at day 21 with $2.5 \mathrm{mg}$ ) was evident by days $3-5$ with once-daily dosing and also sustained throughout the dosing period. These reductions were comparable to those previously reported for alendronate. ${ }^{83,84}$

Two additional osteoclastic biomarkers were evaluated: 1CTP and serum TRAP5b. ODN produced a rapid and dosedependent increase in serum 1CTP, consistent with the role of cathepsin K in the degradation of 1CTP. Neither weekly nor daily dosing of ODN changed serum TRAP5b levels during 3 weeks of dosing. This agreed with previous studies that showed that osteoclast number was either unaffected or tended to increase in cathepsin K-null mice. ${ }^{48}$

In contrast to the results relating to biomarkers of bone resorption, no significant effect was observed with serum bone formation markers, BSAP, and osteocalcin, supporting the idea that this inhibitor is capable of dissociating these two processes.

Data from the two Phase I studies showed that ODN was well tolerated. ${ }^{33,80-82}$ There was no difference in adverse effects between placebo and ODN. ODN had a long apparent half-life $\left(t_{1 / 2}\right)$ of $\sim 66-93$ hours across all doses and regimens studied. Trough concentration data suggested that steadystate conditions were reached in the third week of dosing with either regimen. The sustained pharmacokinetics and pharmacodynamics of ODN supported the adoption of a once-weekly regimen for the treatment of diseases associated with bone loss, given that the once-daily regimen showed no obvious advantage over the once-weekly regimen.

\section{Phase II trials}

\section{Two-year results of Phase II trial}

This was a double-blind, randomized, placebo-controlled trial of 12 months duration with an extension period of 12 months to evaluate the safety and efficacy of weekly doses of placebo or $3,10,25$, or $50 \mathrm{mg}$ of ODN on BMD and biomarkers of skeletal remodeling..$^{85}$ It recruited 399 postmenopausal women aged between 45 and 85 years (mean age 63 years), with a T-score of less than -2 but not less than -3.5 at any site. All patients received vitamin $D$ with calcium supplementation as needed. The primary objective was change in bone mass in the lumbar spine and secondary objectives were changes in BMD in other sites, changes in bone remodeling and adverse treatment effects. A total of 331 (83\%) subjects completed 12 months of treatment and 320 participated in the extension study, which was completed by $270(70 \%)$ at 24 months. Twenty-four months of treatment produced progressive doserelated increases in BMD. With the $50 \mathrm{mg}$ dose of ODN, lumbar spine and total hip BMD increased 5.5\% and 3.2\% respectively, whereas BMD at these sites was unchanged with placebo. Resorption markers fell in a dose-dependent manner. The urinary NTX/Cr ratio decreased by $52 \%$, while the BSAP levels decreased initially but then recovered gradually from month 6 onward to reach $-13 \%$ with the $50 \mathrm{mg}$ dose at month $24 .{ }^{85}$ Significant difference from control for BSAP was observed only for the $50 \mathrm{mg}$ group. The decrease in BSAP level associated with ODN treatment was less than what is typically seen with other antiresorptive agents, such as bisphosphonates. ${ }^{86}$ The safety and tolerability of ODN generally were similar to those of placebo.

\section{Three-year results of Phase II trial}

At the end of 2 years, a 1-year extension study was carried out to further assess ODN efficacy, safety, and the effects of discontinuing therapy. After 2 years, patients $(n=189)$ were re-randomized to ODN $50 \mathrm{mg}$ weekly or placebo for another year in such a way that some participants received placebo for the entire 3 years (PLB/PLB), some were treated with ODN for the entire 3 years (ODN/ODN), and some received ODN $50 \mathrm{mg}$ for 2 years followed by placebo (ODN/PLB) for 1 year. ${ }^{87}$

Women in the ODN/ODN group showed further improvement in BMD and the cumulative gain in BMD after 3 years of treatment with ODN $50 \mathrm{mg}$ was $7.9 \%$ at the lumbar spine, $5.8 \%$ at the total hip, $5.0 \%$ at the femoral neck, and $7.4 \%$ at the trochanter. Urine NTX/Cr remained suppressed at year 3 $(-50.5 \%)$ compared with a $17.5 \%$ decline for those who received placebo for the 3-year period (PLB/PLB). TRAP5b levels were not significantly different from the placebo group and bone formation markers returned to near baseline.

In the ODN/PLB group, women who were previously treated with ODN $50 \mathrm{mg}$ for 2 years showed significant bone loss in all sites and this was most rapid during the first 6 months after discontinuation of active treatment. BMD at 
the lumbar spine, total hip, and trochanter returned to baseline levels after 12 months off medication, although femoral neck BMD remained slightly increased $(+2.3 \%)$. After ODN discontinuation at month 24 , bone turnover markers increased transiently above baseline, but this increase largely resolved by month 36 . The results of this 1-year extension showed that ODN effects were reversible; bone resorption increased transiently and BMD decreased following treatment discontinuation. ${ }^{87}$ The rapid reversibility observed upon discontinuation of ODN was similar to that seen with most other antiresorptive agents such as estrogens, selective estrogen receptor modulators, and denosumab but not oral bisphosphonates or zoledronic acid. ${ }^{2,3,88-91}$

Clinical adverse experiences (AEs) were reported by $150(79.4 \%)$ of the 189 extension participants. The most common clinical AEs, regardless of treatment group, were back pain $(10.1 \%)$, arthralgia $(7.9 \%)$, pain in an extremity $(8.5 \%)$, and nasopharyngitis $(9.5 \%)$. The incidence of adverse experiences of any type generally was balanced between the $50 \mathrm{mg}$ ODN and placebo groups. Eight patients (4.2\%; four placebo, four ODN) discontinued study therapy owing to a clinical AE; discontinuations were not due to any one particular clinical AE. ${ }^{87}$

\section{Five-year results of Phase II trial}

At the end of 3 years, the Phase II trial was extended for a further 2 years. ${ }^{92}$ After 5 years, women who received ODN $50 \mathrm{mg}$ continuously from year $1(\mathrm{n}=13)$, showed BMD increases from baseline of $11.9 \%$ at the lumbar spine, $9.8 \%$ at the femoral neck, $10.9 \%$ at the hip trochanter, and $8.5 \%$ at the total hip. Additionally, women treated continuously with ODN $50 \mathrm{mg}$ maintained a low level of urine NTX/Cr ( $-67.4 \%$ from baseline) through 5 years of treatment; while levels of serum BSAP remained only slightly reduced relative to baseline $(-15.3 \%)$. In women who were switched from ODN to placebo after the 2-year base study $(n=14)$, BMD gains were reversed.

Pooled data showed no statistical difference in the incidence of AEs and serious AEs between the placebo and ODN groups. None of the women in the placebo group and two women $(3 \%)$ in the ODN group discontinued the study drug due to an AE. The incidence of skin-related adverse experiences was $17 \%$ and $12 \%$ in the placebo and ODN groups, respectively. ${ }^{92}$

\section{Potential off-target effects}

While cathepsin $\mathrm{K}$ is highly expressed in osteoclasts, very low levels exist in other adult tissues, including the heart, liver, skeletal muscle, placenta, ovary, testis, small intestine, and colon as well as embryonic lung and neonatal dermal fibroblasts. ${ }^{93-96}$ It is also expressed in synovial fibroblasts and macrophages of rheumatoid arthritic joints and breast and prostate tumors. ${ }^{97-99}$ Therefore, inhibition of cathepsin $\mathrm{K}$ could affect the turnover of type I collagen in organs other than bone. Indeed, histological analysis of human pycnodysostosis tissue specimens revealed the accumulation of collagen fibrils not only in osteoclasts but also in various types of fibroblasts. ${ }^{100}$ Cathepsin $\mathrm{K}$ participates in the degradation of extracellular matrix of the lung and may be involved in the pathogenesis of pulmonary fibrosis as suggested by a more pronounced pulmonary fibrosis in cathepsin K-null mice, compared with their wild-type littermates. ${ }^{101}$ In contrast, when challenged with bleomycin, mice overexpressing cathepsin $\mathrm{K}$ had a lower degree of pulmonary fibrosis than wild-type mice. ${ }^{102}$ The expression of cathepsin $\mathrm{K}$ in dermal fibroblasts may account for some of the adverse effects seen with cathepsin $\mathrm{K}$ inhibition in clinical trials. ${ }^{103}$ However, the degradation of collagen by fibroblasts appears to be a predominantly lysosomal event and this may explain the advantage of the non-lysosomotropic ODN over balicatib. ${ }^{97}$ The ODN clinical trials reported neither skin- nor lungrelated adverse side effects, although the trials were limited by the small number of subjects treated..$^{85,87}$

Preliminary findings suggesting that cathepsin $\mathrm{K}$ appears to be involved in thyroid hormone synthesis, blood pressure regulation, and certain brain functions are also of concern for the long-term use of anti-osteoporotic cathepsin $\mathrm{K}$ inhibitors. ${ }^{52}$ Cathepsin $\mathrm{K}$ is expressed in the thyroid epithelium and the protease is likely involved in thyroid-globulin processing as revealed in studies using cathepsin $\mathrm{K}$ deficient mice. ${ }^{104,105}$ Cathepsin K messenger RNA is detectable in all brain regions of wild-type mice, so cathepsin $\mathrm{K}$ activity could have an important impact on the development and maintenance of the central nervous system. Deletion of cathepsin $\mathrm{K}$ in mice led to deregulation of related proteases such as cathepsin B and L, resulting in a wide range of molecular and cellular changes in the central nervous system. An overall induction of the dopaminergic system was found in cathepsin K-deficient mice, which exhibited reduced anxiety levels as well as short- and long-term memory impairments in behavioral assessments. ${ }^{106}$

Cathepsin $\mathrm{K}$ is the only known mammalian cysteine cathepsin that exhibits a potent kininase activity in vitro. ${ }^{107}$ Kinins are short-term mediators involved in various physiological and pathophysiological events including vasodilatation and constriction of smooth muscle, cardiac homeostasis, 
regulation of blood pressure, and proinflammatory properties in the lung. In rats, cathepsin $\mathrm{K}$ modulates the bradykinindependent contraction of isolated bronchial smooth muscles and impairs bradykinin-induced transient falls in systemic blood pressure. Since bradykinin induces bronchial constriction and hyper-responsiveness in asthmatic patients, cathepsin K may have a positive effect during an asthma crisis by inactivating pro-inflammatory kinins. Thus, inhibition of cathepsin $\mathrm{K}$ could potentially impair the metabolism of regulatory peptides such as kinins.

Finally, cathepsin $\mathrm{K}$ inhibitors are metabolized by enzymes such as the cytochrome CYP3 A4, making them susceptible to pharmacokinetic interactions with other drugs. ${ }^{60,108}$

\section{Potential uses for cathepsin $\mathrm{K}$ inhibitors}

There is potential for cathepsin $\mathrm{K}$ inhibitors to be used in the treatment of metastatic bone disease as well as in osteoarthritis and rheumatoid arthritis.

Metastatic bone disease is characterized by very high levels of bone turnover in proximity to tumors. ${ }^{109}$ Bone resorption inhibitors such as bisphosphonates, and more recently denosumab, have demonstrated their value as adjunctive therapy in preventing bone loss and reducing disease recurrence in patients with breast cancer. ${ }^{10-114}$ Cathepsin $\mathrm{K}$ inhibitors could have a role in the treatment of tumor metastases as well, since cathepsin $\mathrm{K}$ is expressed in breast and prostate tumors, although their role is not yet known. ${ }^{98,99,115}$

Cathepsin $\mathrm{K}$ expression is increased in synovial tissue isolated from joints of human osteoarthritis patients and is specifically found in synovial fibroblasts and articular chondrocytes. ${ }^{116}$ Cathepsin $\mathrm{K}$ not only efficiently degrades type II collagen but also degrades aggrecan at acidic $\mathrm{pH}$, suggesting a possible role in articular cartilage degradation. ${ }^{117}$ In rheumatoid arthritis models, overexpression of cathepsin $\mathrm{K}$ led to spontaneous synovitis and cartilage erosion, while cathepsin K-null mice in the collagen-induced arthritis model revealed decreased bone and articular cartilage resorption, suggesting that cathepsin $\mathrm{K}$ inhibition could be beneficial in this context. ${ }^{52,118}$

\section{Discussion}

Cathepsin K was identified as a therapeutic target for the treatment of osteoporosis because of its key role in the resorption of the organic matrix of bone. Targeting one particular function of the osteoclast rather than its production or survival has conferred some theoretical advantages over the antiresorptive agents currently in use.
Evidence to date has shown that selective cathepsin $\mathrm{K}$ inhibitors substantially reduced bone resorption by preventing cathepsin $\mathrm{K}$ degradation of type I collagen in several animal models and in clinical trials. At 36 months, increases in BMD similar to those of zoledronate and denosumab were observed, although these changes are not from head-to-head comparisons. ${ }^{19,87,119}$ However, cathepsin $\mathrm{K}$ inhibition has shown a quality that is not present among other classes of antiresorptive agents in that it has resulted in greater suppression of bone resorption than bone formation, suggesting a dissociation between bone resorption and bone formation. Even after 5 years of treatment with ODN in humans, while lumbar spine and hip BMD increases correlated with sustained suppression of bone resorption, there was little suppression of bone formation markers, in comparison with the known reduction of these markers by bisphosphonates. ${ }^{120,121}$ In OVX monkeys, ODN not only suppressed bone resorption but also showed a compartment-specific action on bone formation with increased periosteal bone formation and cortical thickness in the femur. These results of the effects of cathepsin $\mathrm{K}$ inhibitors are consistent with the dissociation of bone resorption and formation, suggesting an additional influence on bone modeling. Whether a similar compartmentspecific action of ODN on bone resorption and formation can be demonstrated in humans remains to be determined.

The exact molecular mechanism(s) linking cathepsin $\mathrm{K}$ inhibition and bone formation remain(s) largely unknown; however, they have been predicted to involve complex networks of cell-cell communications. ${ }^{122}$ Histomorphometric and serum TRAP5b data showed that cathepsin K inhibition, unlike the actions of bisphosphonates and denosumab, did not reduce the number of osteoclasts or affect their survival, thereby providing a possible mechanism by which bone formation can be uncoupled from bone resorption. Khosla hypothesized that in the setting of ODN treatment, while the reduction in bone resorption would lead to a reduction in the release of growth factors from the bone matrix, direct communication between non-resorbing osteoclasts and osteoblasts through the ephrin 2-Eph B4 system may not be affected. ${ }^{12-14,123}$ The same may be true of coupling factors, if they are also secreted by non-resorbing osteoclasts. Thus, the net effect of cathepsin $\mathrm{K}$ inhibition on bone formation could depend on offsetting the effects of the loss of growth factor release from bone matrix with the ongoing, perhaps enhanced, effects of coupling factors from the increased numbers of relatively healthy osteoclasts. Furthermore, different remodeling or modeling rates of specific bone surfaces could be linked to the compartment-specific action of ODN on 
bone formation. In trabecular bone, with its high remodeling rate, and where inhibition of bone resorption was associated with reduction in bone formation, the release of growth factors from the bone matrix may be particularly important. ${ }^{75,76}$ On periosteal surfaces, however, where the remodeling rate is much lower and the activity is predominantly modeling, the direct stimulatory effects of osteoclasts on osteoblasts could be responsible for the increased periosteal bone formation and cortical thickness. ${ }^{5,124}$

Bone biopsies of subjects with pycnodysostosis show severe osteosclerosis, large amounts of undigested mineralized matrix, and dysfunctional bone remodeling, which may contribute to the increase in fragility fractures. ${ }^{125}$ However, the relevance of these findings in pycnodysostosis patients, who have a lifelong deficiency of the enzyme, to any potential impact on bone strength in patients with osteoporosis treated with cathepsin $\mathrm{K}$ inhibitors is not known.

The onset and resolution for the antiresorptive effect of cathepsin $\mathrm{K}$ inhibitors were rapid. ${ }^{73,87}$ While a rapid resolution of effect might be preferable if there are concerns about side effects with prolonged exposure, it could also increase the risk of fracture shortly after discontinuation of treatment. This is particularly important because intended and unintended interruptions in therapy, including noncompliance, are very common in clinical practice. ${ }^{126}$

If cathepsin $\mathrm{K}$ inhibitors are safe and at least as effective in fracture reduction as other inhibitors, they could offer theoretical advantages over bisphosphonates. For instance, ODN and other selective cathepsin $\mathrm{K}$ inhibitors might be more effectively combined with anabolic therapy like PTH than resorption inhibitors such as bisphosphonates and denosumab, which lead to inhibition of bone formation..$^{79,127}$

\section{Conclusion}

Available data suggest that cathepsin K inhibition could be a promising intervention with which to treat osteoporosis. Phase I and II studies conducted in postmenopausal women showed ODN to be safe and well tolerated. It is orally available and effective in a once-weekly dose. After 5 years, women who received ODN $50 \mathrm{mg}$ weekly showed significant BMD increases at the lumbar spine and total hip. Antiresorptive activity, shown by the low level of urine bone resorption marker, NTX/Cr, was maintained through 5 years of treatment, while levels of serum bone-specific alkaline phosphatase remained only slightly reduced relative to baseline. In women who were switched from ODN to placebo after 2 years, bone turnover markers reverted to baseline levels after 12 months off medication. Adverse experiences in the ODN-treated group were not significantly different from the placebo group. However, there is yet no fracture data for ODN. Three Phase III studies with ODN are ongoing, two in postmenopausal women (ClinicalTrials.gov registration numbers NCT00529373 and NCT00729183) and one in men (NCT0112600) to assess its safety, efficacy and effects on fracture risk. ${ }^{128-130}$ The results of the "BMD efficacy and safety of odanacatib in postmenopausal women (0822-031)" trial, NCT00529373, are expected in the later half of 2012. This is a clinical, randomized, double-blind trial with 16,716 patients. The target population is postmenopausal osteoporotic women aged $\geq 65$ years not previously treated for osteoporosis. ODN at a dose of $50 \mathrm{mg}$ weekly will be used and placebo will include calcium and vitamin $\mathrm{D}$. The primary objective of the study is the reduction in osteoporotic fractures (vertebral, non-vertebral, and hip). These ongoing fracture-outcome studies are necessary to determine whether the increased bone mass demonstrated in the Phase II studies is translatable into better fracture-risk reduction. ${ }^{82,122}$

\section{Disclosure}

The author reports no conflicts of interest in this work.

\section{References}

1. McClung MR. Bisphosphonates. Endocrinol Metab Clin North Am. 2003;32(1):253-271.

2. Khosla S, Burr D, Cauley J, et al; American Society for Bone and Mineral Research. Bisphosphonate-associated osteonecrosis of the jaw: report of a task force of the American Society for Bone and Mineral Research. J Bone Miner Res. 2007;22(10):1479-1491.

3. Shane E, Burr D, Ebeling PR, et al; American Society for Bone and Mineral Research. Atypical subtrochanteric and diaphyseal femoral fractures: report of a task force of the American Society for Bone and Mineral Research. J Bone Miner Res. 2010;25(11):2267-2294.

4. Vahle JL, Sato M, Long GG, et al. Skeletal changes in rats given daily subcutaneous injections of recombinant human parathyroid hormone (1-34) for 2 years and relevance to human safety. Toxicol Pathol. 2002;30(3):312-321.

5. Baron R, Hesse E. Update on bone anabolics in osteoporosis treatment: rationale, current status, and perspectives. J Clin Endocrinol Metab. 2012;97(2):311-325.

6. Martin TJ, Sims NA, Ng KW. Regulatory pathways revealing new approaches to the development of anabolic drugs for osteoporosis. Osteoporos Int. 2008;19(8):1125-1138.

7. Walker EC, McGregor NE, Poulton IJ, et al. Cardiotrophin-1 is an osteoclast-derived stimulus of bone formation required for normal bone remodeling. J Bone Miner Res. 2008;23(12):2025-2032.

8. Pederson L, Ruan M, Westendorf JJ, Khosla S, Oursler MJ. Regulation of bone formation by osteoclasts involves Wnt/BMP signaling and the chemokine sphingosine-1-phosphate. Proc Natl Acad Sci U S A. 2008;105(52):20764-20769.

9. Negishi-Koga T, Shinohara M, Komatsu N, et al. Suppression of bone formation by osteoclastic expression of semaphorin 4D. Nat Med. 2011;12(11):1473-1480.

10. Tang Y, Wu X, Lei W, et al. TGF-beta1-induced migration of bone mesenchymal stem cells couples bone resorption with formation. Nat Med. 2009;15(7):757-765. 
11. Baron R, Ferrari S, Russell RG. Denosumab and bisphosphonates: different mechanisms of action and effects. Bone. 2011;48(4): 677-692.

12. Zhao C, Irie N, Takada Y, et al. Bidirectional ephrinB2-EphB4 signaling controls bone homeostasis. Cell Metab. 2006;4(2):111-121.

13. Martin TJ, Allan EH, Ho PW, et al. Communication between ephrinB2 and EphB4 within the osteoblast lineage. Adv Exp Med Biol. 2010;658:51-60.

14. Sims NA. EPHs and ephrins: many pathways to regulate osteoblasts and osteoclasts. Bonekey Osteovision. 2010;7(9):304-313.

15. Khosla S, Westendorf JJ, Oursler MJ. Building bone to reverse osteoporosis and repair fractures. J Clin Invest. 2008;118(2):421-428.

16. Cranney A, Guyatt G, Griffith L, Wells G, Tugwell P, Rosen C; Osteoporosis Methodology Group and The Osteoporosis Research Advisory Group. Meta-analyses of therapies for postmenopausal osteoporosis. IX: Summary of meta-analyses of therapies for postmenopausal osteoporosis. Endocr Rev. 2002;23(4):570-578.

17. Rosen CJ. Clinical practice. Postmenopausal osteoporosis. $N$ Engl J Med. 2005;353(6):595-603.

18. Raisz LG. Pathogenesis of osteoporosis: concepts, conflicts, and prospects. J Clin Invest. 2005;115(12):3318-3325.

19. Black DM, Delmas PD, Eastell R, et al; HORIZON Pivotal Fracture Trial. Once-yearly zoledronic acid for treatment of postmenopausal osteoporosis. N Engl J Med. 2007;356(18):1809-1822.

20. Delmas PD. Treatment of postmenopausal osteoporosis. Lancet. 2002;359(9322):2018-2026

21. Lewiecki EM. New targets for intervention in the treatment of postmenopausal osteoporosis. Nat Rev Rheumatol. 2011;7(11):631-638.

22. Neer RM, Arnaud CD, Zanchetta JR, et al. Effect of parathyroid hormone (1-34) on fractures and bone mineral density in postmenopausal women with osteoporosis. N Engl J Med. 2001;344(19):1434-1441.

23. Bauer DC, Garnero P, Bilezikian JP, et al. Short-term changes in bone turnover markers and bone mineral density response to parathyroid hormone in postmenopausal women with osteoporosis. J Clin Endocrinol Metab. 2006;91(4):1370-1375.

24. Tolar J, Teitelbaum SL, Orchard PJ. Osteopetrosis. $N$ Engl J Med. 2004;351(27):2839-2849.

25. Zhao H, Kitaura H, Sands MS, Ross FP, Teitelbaum SL, Novack DV. Critical role of beta3 integrin in experimental postmenopausal osteoporosis. J Bone Miner Res. 2005;20(12):2116-2123.

26. Marzia M, Sims NA, Voit S, et al. Decreased c-Src expression enhances osteoblast differentiation and bone formation. J Cell Biol. 2000;151(2):311-320.

27. Schaller S, Henriksen K, Sørensen MG, Karsdal MA. The role of chloride channels in osteoclasts: $\mathrm{ClC}-7$ as a target for osteoporosis treatment. Drug News Perspect. 2005;18(8):489-495.

28. Brockstedt H, Bollerslev J, Melsen F, Mosekilde L. Cortical bone remodeling in autosomal dominant osteopetrosis: a study of two different phenotypes. Bone. 1996;18(1):67-72.

29. Del Fattore A, Peruzzi B, Rucci N, et al. Clinical, genetic, and cellular analysis of 49 osteopetrotic patients: implications for diagnosis and treatment. J Med Genet. 2006;43(4):315-325.

30. Reiser J, Adair B, Reinheckel T. Specialized roles for cysteine cathepsins in health and disease. J Clin Invest. 2010;120(10):3421-3431.

31. Brömme D, Okamoto K. Human cathepsin O2, a novel cysteine protease highly expressed in osteoclastomas and ovary molecular cloning, sequencing and tissue distribution. Biol Chem Hoppe Seyler. 1995;376(6):379-384.

32. Gauthier JY, Chauret N, Cromlish W, et al. The discovery of odanacatib (MK-0822), a selective inhibitor of cathepsin K. Bioorg Med Chem Lett. 2008;18(3):923-928.

33. Rodan SB, Duong LT. Cathepsin K - a new molecular target for osteoporosis. Bonekey Osteovision. 2008;5(1):16-24.

34. Yamaza T, Goto T, Kamiya T, Kobayashi Y, Sakai H, Tanaka T. Study of immunoelectron microscopic localization of cathepsin $\mathrm{K}$ in osteoclasts and other bone cells in the mouse femur. Bone. 1998;23(6): 499-509.
35. Vääräniemi J, Halleen JM, Kaarlonen K, et al. Intracellular machinery for matrix degradation in bone-resorbing osteoclasts. J Bone Miner Res. 2004;19(9):1432-1440.

36. Xia L, Kilb J, Wex H, et al. Localization of rat cathepsin K in osteoclasts and resorption pits: inhibition of bone resorption and cathepsin K-activity by peptidyl vinyl sulfones. Biol Chem. 1999;380(6):679-687.

37. Garnero P, Borel O, Byrjalsen I, et al. The collagenolytic activity of cathepsin $\mathrm{K}$ is unique among mammalian proteinases. J Biol Chem. 1998;273(48):32347-32352.

38. Furuyama N, Fujisawa Y. Regulation of collagenolytic cysteine protease synthesis by estrogen in osteoclasts. Steroids. 2000;65(7):371-378.

39. Troen BR. The regulation of cathepsin K gene expression. Ann NY Acad Sci. 2006;1068:165-172.

40. Fujisaki K, Tanabe N, Suzuki N, et al. Receptor activator of NF-kappaB ligand induces the expression of carbonic anhydrase II, cathepsin K, and matrix metalloproteinase-9 in osteoclast precursor RAW264.7 cells. Life Sci. 2007;80(14):1311-1318.

41. Maroteaux P, Lamy M. 2 cases of a condensing osseous disease: pycnodysostosis. Arch Fr Pediatr. 1962;19:267-274. French.

42. Gelb BD, Shi GP, Chapman HA, Desnick RJ. Pycnodysostosis, a lysosomal disease caused by cathepsin K deficiency. Science. 1996;273(5279):1236-1238.

43. Motyckova G, Fisher DE. Pycnodysostosis: role and regulation of cathepsin $\mathrm{K}$ in osteoclast function and human disease. Curr Mol Med. 2002;2(5):407-421.

44. Nishi Y, Atley L, Eyre DE, et al. Determination of bone markers in pycnodysostosis: effects of cathepsin $\mathrm{K}$ deficiency on bone matrix degradation. J Bone Miner Res. 1999;14(11):1902-1908.

45. Saftig P, Hunziker E, Wehmeyer O, et al. Impaired osteoclastic bone resorption leads to osteopetrosis in cathepsin-K-deficient mice. Proc Natl Acad Sci U S A. 1998;95(23):13453-13458.

46. Gowen M, Lazner F, Dodds R, et al. Cathepsin K knockout mice develop osteopetrosis due to a deficit in matrix degradation but not demineralization. J Bone Miner Res. 1999;14(10):1654-1663.

47. Chen W, Yang S, Abe Y, et al. Novel pycnodysostosis mouse model uncovers cathepsin $\mathrm{K}$ function as a potential regulator of osteoclast apoptosis and senescence. Hum Mol Genet. 2007;16(4):410-423.

48. Pennypacker B, Shea M, Liu Q, et al. Bone density, strength, and formation in adult cathepsin K (-/-) mice. Bone. 2009;44(2):199-207.

49. Kiviranta R, Morko J, Uusitalo H, Aro HT, Vuorio E, Rantakokko J. Accelerated turnover of metaphyseal trabecular bone in mice overexpressing cathepsin K. J Bone Miner Res. 2001;16(8):1444-1452.

50. Yamashita DS, Dodds RA. Cathepsin K and the design of inhibitors of cathepsin K. Curr Pharm Des. 2000;6(1):1-24.

51. Tavares FX, Boncek V, Deaton DN, et al. Design of potent, selective, and orally bioavailable inhibitors of cysteine protease cathepsin $\mathrm{k}$. J Med Chem. 2004;47(3):588-599.

52. Brömme D, Lecaille F. Cathepsin K inhibitors for osteoporosis and potential off-target effects. Expert Opin Investig Drugs. 2009;18(5):585-600.

53. Russell RG, Watts NB, Ebetino FH, Rogers MJ. Mechanisms of action of bisphosphonates: similarities and differences and their potential influence on clinical efficacy. Osteoporos Int. 2008;19(6): 733-759.

54. Falgueyret JP, Desmarais S, Oballa R, et al. Lysosomotropism of basic cathepsin $\mathrm{K}$ inhibitors contributes to increased cellular potencies against off-target cathepsins and reduced functional selectivity. J Med Chem. 2005;48(24):7535-7543.

55. Black WC, Percival MD. The consequences of lysosomotropism on the design of selective cathepsin $\mathrm{K}$ inhibitors. Chembiochem. 2006;7(10):1525-1535.

56. Desmarais S, Black WC, Oballa R, et al. Effect of cathepsin k inhibitor basicity on in vivo off-target activities. Mol Pharmacol. 2008;73(1):147-156.

57. Li CS, Deschenes D, Desmarais S, et al. Identification of a potent and selective non-basic cathepsin K inhibitor. Bioorg Med Chem Lett. 2006;16(7):1985-1989. 
58. Kim TS, Tasker AS. Non-covalent cathepsin $\mathrm{K}$ inhibitors for the treatment of osteoporosis. Curr Top Med Chem. 2006;6(4):355-360.

59. Marquis RW, Ru Y, LoCastro SM, et al. Azepanone-based inhibitors of human and rat cathepsin K. J Med Chem. 2001;44(9):1380-1395.

60. Podgorski I. Future of anticathepsin K drugs: dual therapy for skeletal disease and atherosclerosis? Future Med Chem. 2009;1(1):21-34.

61. Stoch SA, Wagner JA. Cathepsin K inhibitors: a novel target for osteoporosis therapy. Clin Pharmacol Ther. 2008;83(1):172-176.

62. Palmer JT, Bryant C, Wang DX, et al. Design and synthesis of tri-ring P3 benzamide-containing aminonitriles as potent, selective, orally effective inhibitors of cathepsin K. J Med Chem. 2005;48(24):7520-7534.

63. Kumar S, Dare L, Vasko-Moser JA, et al. A highly potent inhibitor of cathepsin K (relacatib) reduces biomarkers of bone resorption both in vitro and in an acute model of elevated bone turnover in vivo in monkeys. Bone. 2007;40(1):122-131.

64. Yamashita DS, Marquis RW, Xie R, et al. Structure activity relationships of 5-, 6-, and 7-methyl-substituted azepan-3-one cathepsin K inhibitors. J Med Chem. 2006;49(5):1597-1612.

65. Stroup G, Jerome C, Yamashita DS, Kumar S. Histomorphometric and biochemical evidence for a cortical bone-forming effect of a cathepsin $\mathrm{K}$ inhibitor in ovariectomized cynomolgus monkeys. J Bone Miner Res. 2005;20(Suppl 1):Abstract F236.

66. Stroup GB, Dare L, Vasko-Moser J, Hoffman S, Kumar S. Repeat daily dosing with a high potent inhibitor of cathepsin K results in significant, transient elevation of plasma PTH in cynomolgus monkeys. $J$ Bone Miner Res. 2006;21(Suppl 1):Abstract SA236.

67. Black WC. Peptidomimetic inhibitors of cathepsin K. Curr Top Med Chem. 2010;10(7):745-751.

68. Jerome C, Missbach M, Gamse R. Balicatib, a cathepsin K inhibitor, stimulates periosteal bone formation in monkeys. Osteoporos Int. 2011;22(12):3001-3011.

69. Adami S, Supronik J, Hala T, et al. Effect of one year treatment with the cathepsin-K inhibitor, balicatib, on bone mineral density (BMD) in postmenopausal women with osteopenia/osteoporosis. J Bone Miner Res. 2006;21(Suppl 1):Abstract S24.

70. Peroni A, Zini A, Braga V, Colato C, Adami S, Girolomoni G. Drug-induced morphea: report of a case induced by balicatib and review of the literature. J Am Acad Dermatol. 2008;59(1):125-129.

71. Yamada H, Mori, Nakanishi Y, et al. Orally active cathepsin K inhibitor, ONO-5344, potently improved bone mineral density not only in trabecular bone but also in cortical bone in ovariectomized cynomolgus monkeys. J Bone Miner Res. 2009;24(Suppl 1):Abstract SA042.

72. Yamada H, Mori H, Kunishige A, et al. Efficacy of ONO-5344, a cathep$\sin \mathrm{K}$ inhibitor, on bone mass and strength in ovariectomized cynomolgus monkeys. J Bone Miner Res. 2010;25(Suppl 1):Abstract SA0438.

73. Eastell R, Nagase S, Ohyama M, et al. Safety and efficacy of the cathepsin K inhibitor ONO-5334 in postmenopausal osteoporosis: the OCEAN study. J Bone Miner Res. 2011;26(6):1303-1312.

74. Pennypacker B, Rodan S, Masarachia P, Rodan G, Kimmel DB. Bone effects of a cathepsin $\mathrm{K}$ inhibitor in the adult estrogen-deficient rabbit. J Bone Miner Res. 2006;21(Suppl 1):Abstract S383.

75. Masarachia PJ, Pennypacker BL, Pickarski M, et al. Odanacatib reduces bone turnover and increases bone mass in the lumbar spine of skeletally mature ovariectomized rhesus monkeys. J Bone Miner Res. 2012;27(3):509-523.

76. Cusick T, Chen CM, Pennypacker BL, et al. Odanacatib treatment increases hip bone mass and cortical thickness by preserving endocortical bone formation and stimulating periosteal bone formation in the ovariectomized adult rhesus monkey. J Bone Miner Res. 2012;27(3):524-537.

77. Alatalo SL, Ivaska KK, Waguespack SG, Econs MJ, Väänänen HK, Halleen JM. Osteoclast-derived serum tartrate-resistant acid phosphatase 5b in Albers-Schonberg disease (type II autosomal dominant osteopetrosis). Clin Chem. 2004;50(5):883-890.

78. Halleen JM, Tiitinen SL, Ylipahkala H, Fagerlund KM, Väänänen HK. Tartrate-resistant acid phosphatase 5b (TRACP 5b) as a marker of bone resorption. Clin Lab. 2006;52(9-10):499-509.
79. Pennypacker B, Wu G, Korn R, Samadfam R, Smith SY, Duong LT. Efficacy of the combination of parathyroid hormone plus odanacatib or alendronate, as compared to the monotherapies in estrogen-deficient rabbits. J Bone Miner Res. 2011;26(Suppl 1):Abstract 1030.

80. Stoch SA, Miller DL, Van Dyck K, et al. Effect of cathepsin K inhibition on bone resorption markers in healthy postmenopausal women. $J$ Bone Miner Res. 2006;21(Suppl 1):Abstract 1224.

81. Stoch SA, Zajic S, Stone J, et al. Effect of the cathepsin K inhibitor odanacatib on bone resorption biomarkers in healthy postmenopausal women: two double-blind, randomized, placebo-controlled phase I studies. Clin Pharmacol Ther. 2009;86(2):175-182.

82. Costa AG, Cusano NE, Silva BC, Cremers S, Bilezikian JP. Cathepsin K: its skeletal actions and role as a therapeutic target in osteoporosis. Nat Rev Rheumatol. 2011;7(8):447-456.

83. Harris ST, Gertz BJ, Genant HK, et al. The effect of short term treatment with alendronate on vertebral density and biochemical markers of bone remodeling in early postmenopausal women. $J$ Clin Endocrinol Metab. 1993;76(6):1399-1406.

84. Schnitzer T, Bone HG, Crepaldi G, et al. Therapeutic equivalence of alendronate $70 \mathrm{mg}$ once-weekly and alendronate $10 \mathrm{mg}$ daily in the treatment of osteoporosis. Alendronate Once-Weekly Study Group. Aging (Milano). 2000;12(1):1-12.

85. Bone HG, McClung MR, Roux C, et al. Odanacatib, a cathepsin-K inhibitor for osteoporosis: a two-year study in postmenopausal women with low bone density. J Bone Miner Res. 2010;25(5):937-947.

86. Lewiecki EM. Odanacatib, a cathepsin K inhibitor for the treatment of osteoporosis and other skeletal disorders associated with excessive bone remodeling. IDrugs. 2009;12(12):799-809.

87. Eisman JA, Bone HG, Hosking DJ, et al. Odanacatib in the treatment of postmenopausal women with low bone mineral density: threeyear continued therapy and resolution of effect. $J$ Bone Miner Res. 2011;26(2):242-251.

88. Neele SJ, Evertz R, De Valk-De Roo G, Roos JC, Netelenbos JC. Effect of 1 year of discontinuation of raloxifene or estrogen therapy on bone mineral density after 5 years of treatment in healthy postmenopausal women. Bone. 2002;30(4):599-603.

89. Bone HG, Bolognese MA, Yuen CK, et al. Effects of denosumab treatment and discontinuation on bone mineral density and bone turnover markers in postmenopausal women with low bone mass. J Clin Endocrinol Metab. 2011;96(4):972-980.

90. Miller PD, Bolognese MA, Lewiecki EM, et al. Effect of denosumab on bone density and turnover in postmenopausal women with low bone mass after long-term continued, discontinued, and restarting of therapy: a randomized blinded phase 2 clinical trial. Bone. 2008;43(2):222-229.

91. Grey A, Bolland MJ, Wattie D, Horne A, Gamble G, Reid IR. The antiresorptive effects of a single dose of zoledronate persist for two years: a randomized, placebo-controlled trial in osteopenic postmenopausal women. J Clin Endocrinol Metab. 2009;94(2):538-544.

92. Binkley N, Gilchrist N, Langdahl B, et al. Treatment with the cathepsin $\mathrm{K}$ inhibitor odanacatib in postmenopausal women with low BMD: 5 year results of a phase 2 trial. J Bone Mineral Res. 2011;26(Suppl 1): Abstract FR0453.

93. Littlewood-Evans A, Kokubo T, Ishibashi O, et al. Localization of cathepsin $\mathrm{K}$ in human osteoclasts by in situ hybridization and immunohistochemistry. Bone. 1997;20(2):81-86.

94. Inaoka T, Bilbe G, Ishibashi O, Tezuka K, Kumegawa M, Kokubo T. Molecular cloning of human cDNA for cathepsin K: novel cysteine proteinase predominantly expressed in bone. Biochem Biophys Res Commun. 1995;206(1):89-96.

95. Bühling F, Waldburg N, Gerber A, et al. Cathepsin K expression in human lung. Adv Exp Med Biol. 2000;477:281-286.

96. Rünger TM, Quintanilla-Dieck MJ, Bhawan J. Role of cathepsin K in the turnover of the dermal extracellular matrix during scar formation. J Invest Dermatol. 2007;127(2):293-297.

97. Hou WS, Li Z, Gordon RE, et al. Cathepsin K is a critical protease in synovial fibroblast-mediated collagen degradation. Am J Pathol. 2001;159(6):2167-2177. 
98. Littlewood-Evans AJ, Bilbe G, Bowler WB, et al. The osteoclastassociated protease cathepsin $\mathrm{K}$ is expressed in human breast carcinoma. Cancer Res. 1997;57(23):5386-5390.

99. Brubaker KD, Vessella RL, True LD, Thomas R, Corey E. Cathepsin K mRNA and protein expression in prostate cancer progression. J Bone Miner Res. 2003;18(2):222-230.

100. Everts V, Hou WS, Rialland X, et al. Cathepsin K deficiency in pycnodysostosis results in accumulation of non-digested phagocytosed collagen in fibroblasts. Calcif Tissue Int. 2003;73(4):380-386.

101. Bühling F, Röcken C, Brasch F, et al. Pivotal role of cathepsin K in lung fibrosis. Am J Pathol. 2004;164(6):2203-2216.

102. Srivastava M, Steinwede K, Kiviranta R, et al. Overexpression of cathepsin $\mathrm{K}$ in mice decreases collagen deposition and lung resistance in response to bleomycin-induced pulmonary fibrosis. Respir Res 2008;9:54.

103. Quintanilla-Dieck MJ, Codriansky K, Keady M, Bhawan J, Rünger TM. Expression and regulation of cathepsin $\mathrm{K}$ in skin fibroblasts. Exp Dermatol. 2009;18(7):596-602.

104. Tepel C, Brömme D, Herzog V, Brix K. Cathepsin K in thyroid epithelial cells: sequence, localization and possible function in extracellular proteolysis of thyroglobulin. J Cell Sci. 2000;113(Pt 24):4487-4498.

105. Friedrichs B, Tepel C, Reinheckel T, et al. Thyroid functions of mouse cathepsins B, K, and L. J Clin Invest. 2003;111(11):1733-1745.

106. Dauth S, Sîrbulescu RF, Jordans S, et al. Cathepsin K deficiency in mice induces structural and metabolic changes in the central nervous system that are associated with learning and memory deficits. $B M C$ Neurosci. 2011;12:74.

107. Lecaille F, Chowdhury S, Purisima E, Brömme D, Lalmanach G. The $\mathrm{S} 2$ subsites of cathepsins $\mathrm{K}$ and $\mathrm{L}$ and their contribution to collagen degradation. Protein Sci. 2007;16(4):662-670.

108. Isabel E, Bateman KP, Chauret N, et al. The discovery of MK-0674, an orally bioavailable cathepsin K inhibitor. Bioorg Med Chem Lett. 2010;20(3):887-892.

109. Roodman GD. Mechanisms of bone metastasis. $N$ Engl J Med 2004;350(16):1655-1664.

110. Eastell R. Breast cancer and the risk of osteoporotic fracture: A paradox. J Clin Endocrinol Metab. 2007;92(1):42-43.

111. Gnant M, Mlineritsch B, Schippinger W, et al; ABCSG-12 Trial Investigators, Marth C. Endocrine therapy plus zoledronic acid in premenopausal breast cancer. N Engl J Med. 2009;360(7):679-691.

112. Brufsky AM, Bosserman LD, Caradonna RR, et al. Zoledronic acid effectively prevents aromatase inhibitor-associated bone loss in postmenopausal women with early breast cancer receiving adjuvant letrozole: Z-FAST study 36-month follow-up results. Clin Breast Cancer. 2009;9(2):77-85.

113. Ellis GK, Bone HG, Chlebowski R, et al. Effect of denosumab on bone mineral density in women receiving adjuvant aromatase inhibitors for non-metastatic breast cancer: subgroup analyses of a phase 3 study. Breast Cancer Res Treat. 2009;118(1):81-87.

114. Santen RJ. Clinical review: Effect of endocrine therapies on bone in breast cancer patients. J Clin Endocrinol Metab. 2011;96(2):308-319.

115. Jensen AB, Wynne C, Ramirez G, et al. The cathepsin K inhibitor odanacatib suppresses bone resorption in women with breast cancer and established bone metastases: results of a 4-week, double-blind, randomized, controlled trial. Clin Breast Cancer. 2010;10(6):452-458.
116. Salminen-Mankonen HJ, Morko J, Vuorio E. Role of cathepsin K in normal joints and in the development of arthritis. Curr Drug Targets. 2007;8(2):315-323.

117. Yasuda Y, Kaleta J, Brömme D. The role of cathepsins in osteoporosis and arthritis: rationale for the design of new therapeutics. Adv Drug Deliv Rev. 2005;57(7):973-993.

118. Morko J, Kiviranta R, Joronen K, Säämänen AM, Vuorio E, SalminenMankonen H. Spontaneous development of synovitis and cartilage degeneration in transgenic mice overexpressing cathepsin K. Arthritis Rheum. 2005;52(12):3713-3717.

119. Cummings SR, San Martin J, McClung MR, et al; FREEDOM Trial. Denosumab for prevention of fractures in postmenopausal women with osteoporosis. N Engl J Med. 2009;361(8):756-765.

120. Bone HG, Bolognese MA, Yuen CK, et al. Effects of denosumab on bone mineral density and bone turnover in postmenopausal women. J Clin Endocrinol Metab. 2008;93(6):2149-2157.

121. Sosa M, Hernández D, Segarra MC, Gómez A, de la Peña E, Betancor P. Effect of two forms of alendronate administration upon bone mass after two years of treatment. J Clin Densitom. 2002;5(1):27-34.

122. Duong LT. Therapeutic inhibition of cathepsin $\mathrm{K}$ - reducing bone resorption while maintaining bone formation. Bonekey Reports. 2012:1. doi:10.1038/bonekey.2012.67.

123. Khosla S. Odanacatib: location and timing are everything. $J$ Bone Miner Res. 2012;27(3):506-508.

124. Balena R, Shih MS, Parfitt AM. Bone resorption and formation on the periosteal envelope of the ilium: a histomorphometric study in healthy women. J Bone Miner Res. 1992;7(12):1475-1482.

125. Fratzl-Zelman N, Valenta A, Roschger P, et al. Decreased bone turnover and deterioration of bone structure in two cases of pycnodysostosis. J Clin Endocrinol Metab. 2004;89(4):1538-1547.

126. Bauer DC. Discontinuation of odanacatib and other osteoporosis treatments: here today and gone tomorrow? J Bone Miner Res. 2011;26(2):239-241.

127. Black DM, Greenspan SL, Ensrud KE, et al; PaTH Study Investigators The effects of parathyroid hormone and alendronate alone or in combination in postmenopausal osteoporosis. $N$ Engl J Med. 2003; 349(13):1207-1215.

128. Merck. A study of MK0822 in postmenopausal women with osteoporosis to assess fracture risk (MK-0822-018 AM4 EXT). In: ClinicalTrials.gov [website on the Internet]. Bethseda, MD: US National Library of Medicine; 2007 [updated March 16, 2012]. Available from: clinicaltrials.gov/ct2/show/NCT00529373. NLM identifier: NCT00529373. Accessed June 6, 2012.

129. Merck. BMD efficacy and safety of odanacatib in postmenopausal women (0822-031). In: ClinicalTrials.gov [website on the Internet]. Bethseda, MD: US National Library of Medicine; 2008 [updated May 14, 2012]. Available from: clinicaltrials.gov/ct2/show/NCT00729183. NLM identifier: NCT00729183. Accessed June 6, 2012.

130. Merck. A study to assess safety and efficacy of odanacatib (MK-0822) in men with osteoporosis (MK-0822-053 AM1). In: ClinicalTrials. gov [website on the Internet]. Bethseda, MD: US National Library of Medicine; 2010 [updated July 14, 2011]. Available from: clinicaltrials. gov/ct2/show/NCT01120600. NLM identifier: NCT01120600. Accessed June 6, 2012
Clinical Interventions in Aging

\section{Publish your work in this journal}

Clinical Interventions in Aging is an international, peer-reviewed journal focusing on evidence-based reports on the value or lack thereof of treatments intended to prevent or delay the onset of maladaptive correlates of aging in human beings. This journal is indexed on PubMed Central, MedLine, the American Chemical Society's 'Chemical Abstracts Ser-

\section{Dovepress}

vice' (CAS), Scopus and the Elsevier Bibliographic databases. The manuscript management system is completely online and includes a very quick and fair peer-review system, which is all easy to use. Visit http://www.dovepress.com/testimonials.php to read real quotes from published authors. 